\title{
Changes of lysosomal membrane permeabilization and lipid metabolism in sidt 2 deficient mice
}

\author{
YU MENG ${ }^{1,2}$, LIZHUO WANG ${ }^{1,2}$ and LIEFENG LING ${ }^{1,2}$ \\ ${ }^{1}$ Anhui Province Key Laboratory of Biological Macro-molecules Research, Wannan Medical College, Wuhu, \\ Anhui 241001; ${ }^{2}$ Department of Biochemistry, Wannan Medical College, Wuhu, Anhui 241002, P.R. China
}

Received October 16, 2017; Accepted March 29, 2018

DOI: $10.3892 /$ etm.2018.6187

\begin{abstract}
The SID1 transmembrane family member 2 (sidt2) deficient mouse model was used to investigate the function of sidt 2 in lysosomal membrane permeabilization and lipid metabolism of liver tissue. The mouse model was established by Cre/LoxP technology. Enzymatic methods were used to analyze the sidt $2^{-/-}$mouse serum lipids, aspartate transaminase, alanine transaminase and serum bilirubin, compared with sidt $2^{+/+}$mice. Defective lipid metabolism and damaged liver functions were observed in the sidt $2^{-/-}$mice. By using hematoxylin and eosin and Oil Red $\mathrm{O}$ staining, changes of morphology were observed in sidt $2^{-/-}$mice with optical microscopy. Transmission electron microscopy was also used. Hepatic steatosis and partial liver tissue apoptosis were observed. The tissue distribution of sidt 2 protein and mRNA was measured in knockout mice. The results indicated that negligible sidt 2 mRNA and protein expression were observed in sidt $2^{-/-}$mice, and that sidt $2^{-/-}$mice had abnormal liver functions. Transmission electron microscopy revealed membrane lipid droplets in the liver cell cytoplasm, and some apoptotic body formation. These results demonstrated that absence of the lysosomal membrane protein sidt 2 led to changes in lysosomal membrane permeabilization and lipid metabolism.
\end{abstract}

\section{Introduction}

The lysosome is an important organelle in cells; it has previously been regarded as the 'garbage disposal' organelle in cells (1), as it contains $>50$ soluble acid hydrolases. The lysosome is now regarded as a key subcellular organelle (2), acting to degrade cellular components through initiation by phagocytosis, autophagy and other pathways (3). The characteristic acidic environment ( $\mathrm{pH} 4.5-5.0)$ of lysosomes provides an

Correspondence to: Miss Lizhuo Wang, Department of Biochemistry, Wannan Medical College, 2 West Wenchang Road, Wuhu, Anhui 241002, P.R. China

E-mail: 19277984@qq.com

Key words: SID1 transmembrane family member $2^{-/}$mice, lysosomal membrane permeabilization, lipid metabolism optimal environment for lysosomal hydrolase activity, and this contributes to macromolecular degradation (4). If the internal $\mathrm{pH}$ changes, the activity of internal hydrolytic enzymes will change, thus affecting the function of the lysosomes. The change of lysosomal function can lead to reactions inside the cell. The lysosomal membrane proteins that are responsible for sustaining membrane integrity and regulating lysosomal function are not completely known. As lysosomal membrane integrity is important for the fate of cells, once it is destroyed by a procedure known as lysosomal membrane permeabilization (LMP), lysosomal content leakage will occur (5). The leakage of lysosomal constituents may be sufficient to trigger cell death (5).

SID1 transmembrane family member 2 (sidt2), a lysosomal membrane protein, has previously been studied (3). Sidt2 is a lysosomal membrane protein. In a previous study, sidt 2 was identified as a novel integral lysosomal membrane protein with a molecular weight of $94 \mathrm{kDa}(6)$. Sidt 2 functions as an integral protein and is associated with signaling pathways, including the PTEN-induced putative kinase and CUP-5 proteins that regulate lysosomal autophagy and apoptosis (3). The present study utilized a sidt 2 deficient mouse model to explore the function and mechanisms of sidt 2 action in liver lipid metabolism and changes of LMP.

\section{Materials and methods}

Animals. Cre mice mated with sidt2 LoxP-Flox-LoxP ${ }^{-/+}$mice to obtain sidt $2^{-/+} \mathrm{Cre}^{+/-}$mice. A total of 100 male and 200 female mice (age, 8-10 weeks; weight, 25-30 g) were purchased from the Shanghai SLAC Laboratory Animal Co., Ltd. (Shanghai, China). Normal male rats can be used for breeding offspring after 8 weeks and females after 10 weeks. The mice were maintained in a controlled temperature $\left(22-25^{\circ} \mathrm{C}\right)$ and humidity (50-60\%) with a $12 \mathrm{~h}$ light/dark cycle and fed a controlled diet and water. The animals had free access to food and water under basic feeding conditions. To prevent the phenotypic effects of Cre mice, the F2 generation of $\mathrm{Sidt}^{-/+}$mice was used to mate with wild-type strain 129 mice (a total of $100 \mathrm{Cre}$ mice and 100 sidt 2 LoxP-Flox-LoxP ${ }^{-/+}$mice were used) and $\mathrm{F} 3$ sidt $2^{-/+} \mathrm{Cre}^{-/}$mice were established. Through the next generation and wild-type mice of the same strain, the Cre genotype was removed and the heterozygous sidt $2^{-/+}$mice of the sidt 2 knockout were obtained. The sidt $2^{-/+}$mice were bred with each 
other to obtain full knockout homozygous sidt $2^{-/-}$mice. Adult F3 generation mice mated with each other to produce the sidt $2^{-/}$mice. Anesthesia was administered in every operation to minimize the pain. Animal experiments were reviewed and approved by Animal Ethics Committee of Wannan Medical College (Wuhu, China).

Reverse transcription-polymerase chain reaction (RT-PCR) analysis. The mice were sacrificed and total RNA was extracted from tissue in the liver, stomach, spleen, heart, kidney, intestine, brain, pancreas and lung, and prepared using an RNA extraction kit (cat. no. SK8652; Sangon Biotech Co., Ltd., Shanghai, China) according to the manufacturer's instructions. A Reverse Transcription kit was purchased from Takara Biotechnology Co., Ltd. (Dalian, China; cat. no. RR037A). The reverse transcription reaction system was made up of $1 \mu \mathrm{l}$ primer and $1 \mu \mathrm{lNTP}$, denaturation occurred at $65^{\circ} \mathrm{C}$ for $5 \mathrm{~min}$ then the mixture was placed on ice for $5 \mathrm{~min}$. A total of $2 \mu \mathrm{l}$ DTT, $4 \mu 1$ reverse transcription buffer and $1 \mu \mathrm{l}$ RNAase inhibitor were added. The mixture was centrifuged at $10,000 \mathrm{x} \mathrm{g}$ for $1 \mathrm{~min}$ at room temperature and incubated at $37^{\circ} \mathrm{C}$ for $2 \mathrm{~min}$. A total of $1 \mu \mathrm{l}$ reverse transcriptase was added and incubated at $70^{\circ} \mathrm{C}$ for $15 \mathrm{~min}$ to perform PCR amplification. The primers used were designed with Primer 5.0 software (Premier Biosoft International, Palo Alto, CA, USA) and synthesized by Sangon Biotech Co., Ltd. Primer sequences for sidt 2 were as follows: Forward, 5'-ATGTGGTGGTGGTAGTGAAG-3', and reverse, 5'-AGATACACCACCACCATCAC-3'. PCR was performed as follows: $5 \mathrm{~min}$ at $95^{\circ} \mathrm{C}$, followed by 34 cycles of $45 \mathrm{sec}$ at $94^{\circ} \mathrm{C}$, $45 \mathrm{sec}$ at $56^{\circ} \mathrm{C}, 1 \mathrm{~min}$ at $72^{\circ} \mathrm{C}$ and $10 \mathrm{~min}$ at $72^{\circ} \mathrm{C}$.

Analysis of blood lipids, serum bilirubin, and concentration of H2O2, $\mathrm{NO}$ and iron in lysosomes. Blood was obtained via retro-orbital bleeding. ELISA kits were used to measure the serum levels of ALT (cat. no. DL-ALT-Mu-48T), HDL-C (cat. no. CSB-E12874m) and LDL-C (cat. no. CSB-E16561r) according to the manufacturer's protocol (all Beyotime Institute of Biotechnology, Haimen, China). Plasma total cholesterol (T-CHOL; cat. no. A111-1), triglyceride (TG; cat. no. F001; Nanjing Jiancheng Institute of Biological Engineering, Nanjing, China), serum bilirubin and serum aspartate aminotransferase (AST; cat. no. P3636; Beyotime Institute of Biotechnology) were determined by ELISA according to the manufacturer's protocol. $\mathrm{H}_{2} \mathrm{O}_{2}$ (cat. no. A007-2), NO (cat. no. A012-1) (both Nanjing Jiancheng Institute of Biological Engineering) and iron $\left(\mathrm{Fe}^{2+}, \mathrm{Fe}^{3+}\right.$ and total $\mathrm{Fe}$; cat. no. ab83366; Abcam, Cambridge, UK) levels in lysosomes were measured using colorimetric assay kits and an iron assay kit according to the manufacturer's protocol. Lysosomes were isolated from mouse livers as previously described (7).

Western blot analysis. To evaluate protein expression, tissues from the liver, stomach, spleen, heart, kidney, intestine, brain, pancreas and lung were homogenized in a lysis buffer (Beyotime Institute of Biotechnology). Homogenates were centrifuged at $12,000 \mathrm{x} \mathrm{g}$ at $4^{\circ} \mathrm{C}$ for $10-20 \mathrm{~min}$. The protein concentration of the test sample was calculated using a BCA assay kit (Pierce; Thermo Fisher Scientific, Inc.) according to the manufacturer's protocol. Western blot analysis was performed as described previously (8). Briefly, $30 \mu \mathrm{g}$ total soluble proteins were separated on $12.5 \%$ SDS-PAGE and transferred onto polyvinylidene fluoride membranes. The membranes were blocked with 5\% skimmed milk at room temperature for $90 \mathrm{~min}$. Membranes were incubated with rabbit anti-sidt2 specific antibodies (1:1,000; SAB1304608; Sigma-Aldrich; Merck KGaA, Darmstadt, Germany) at $4^{\circ} \mathrm{C}$ overnight and then with horseradish peroxidase-conjugated goat anti-rabbit secondary antibodies (1:3,000; A0208; Beyotime Institute of Biotechnology) at room temperature for $1 \mathrm{~h}$. Antibodies specific to $\beta$-actin (1:5,000; A5441; Sigma-Aldrich; Merck KGaA) served as an internal control. The target proteins were visualized using an enhanced chemiluminescence Western Blotting Substrate (32106; Thermo Fisher Scientific, Inc., Waltham, MA, USA). ImageJ 1.48u software (National Institutes of Health, Bethesda, MD, USA) was used for densitometry analysis.

Histological studies. Liver tissue samples were stored in liquid nitrogen. The sections were fixed with formaldehyde-calcium for $10 \mathrm{~min}$ at $4^{\circ} \mathrm{C}$ and cryostat sectioned at a thickness of $10 \mu \mathrm{m}$ onto poly-L-lysine slides for lipid deposition analyses using Oil Red O staining. The frozen sections were rewarmed and dried for $10 \mathrm{~min}$ and incubated with $100 \%$ isopropanol for $5 \mathrm{~min}$, then incubated with $0.5 \%$ oil red $\mathrm{O}$ solution for 7-8 min at $60^{\circ} \mathrm{C}$. Additional sections were stained with hematoxylin and eosin (H\&E) for $5 \mathrm{~min}$ at room temperature and examined by light microscopy at magnification, $\mathrm{x} 200$.

Transmission electron microscopy (TEM). Liver tissue samples were fixed in $2.5 \%$ glutaraldehyde for $2 \mathrm{~h}$ at $4^{\circ} \mathrm{C}$, treated with $1 \%$ osmium tetroxide, dehydrated and embedded in Durcupan (Sigma-Aldrich; Merck KGaA) for $48 \mathrm{~h}$ at $60^{\circ} \mathrm{C}$, then sectioned $(60 \mathrm{~nm})$. The sections were stained with dioxygen staining for $20 \mathrm{~min}$ and lead citrate for $7 \mathrm{~min}$ at room temperature, then mounted on Gu-grids and examined by electron microscopy (EM-1200EX; JEOL, Ltd., Tokyo, Japan; magnification, $\mathrm{x} 12,000)$.

Statistical analyses. All data are expressed as the mean \pm standard error of the mean. One-way analysis of variance followed by Tukey's post hoc test was used for comparisons among multiple groups. The comparison between two groups of data was performed using the Student's t-test for pairwise comparison. $\mathrm{P}<0.05$ was considered to indicate a statistically significant difference. SPSS 16.0 (SPSS, Inc., Chicago, IL, USA) was used to perform analysis.

\section{Results}

Tissue distribution of sidt 2 protein and production of sidt 2 knockout mice. In the brain, intestinal, and lung tissues the expression levels are lower, with the lowest expression observed in the heart (Fig. 1A and B). Sidt2 gene whole body knockout mice (sidt $2^{--}$) were generated using the Cre/LoxP system. The mRNA and protein expression levels of sidt 2 were examined using RT-PCR and western blotting, respectively. The results indicated that negligible sidt $2 \mathrm{mRNA}$ and protein expressions were observed in sidt $2^{--}$mice (Fig. 1C and D). To identify RNA-level knockout mice, cDNA was obtained via RT-PCR by extracting RNA from sidt $2^{+/-}$and sidt $2^{-/-}$mouse liver tissues 


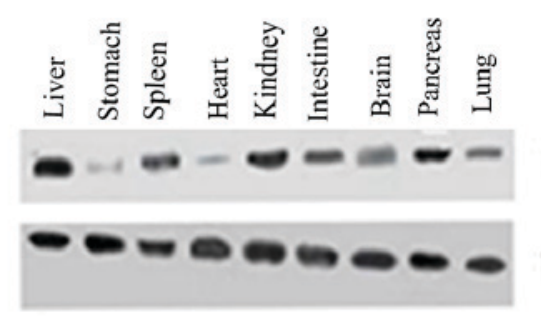

$\mathrm{C}$

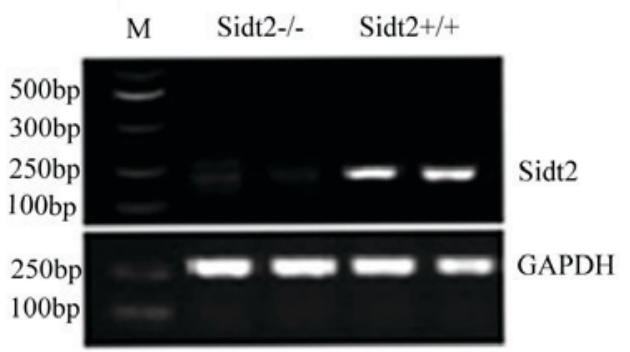

B

The relative protein level

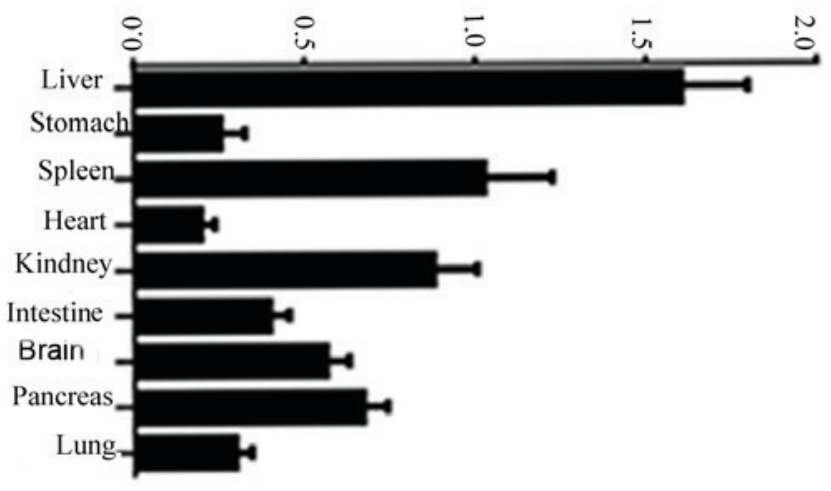

D

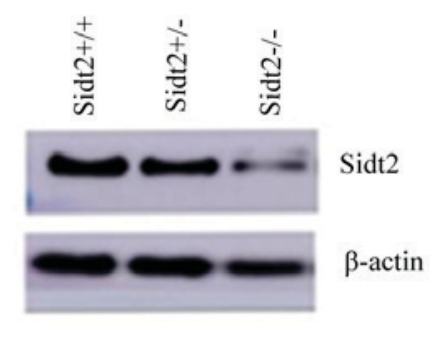

Figure 1. The tissue distribution of sidt2 protein in sidt2 knockout mice. (A and B) Analysis of tissue distribution of sidt2 protein by western blotting. The (C) mRNA and (D) protein expression levels of sidt2 were examined via reverse transcription and western blotting, respectively. Sidt2, SID1 transmembrane family member 2. Data are presented as the mean \pm standard error of the mean $(n=8)$.

and using this as a template. The identification of the reaction system was performed via PCR. Primers were designed with sidt 2 gene exon 2 as a template. The PCR product was $250 \mathrm{bp}$ in length. Sidt $2^{+/+}$mice yielded products $250 \mathrm{bp}$ in size. The sidt 2 knockout homozygous mouse were not able to amplify the product, as indicated in Fig. 1C.

Changes of serum biochemical parameters in sidt $2^{-/}$mice. Measurements of sidt $2^{-/}$mouse serum AST, alanine transaminase (ALT), T-CHOL, TG, high density lipoprotein cholesterol (HDL-C), low density lipoprotein cholesterol (LDL-C), total bilirubin (T-Bil), indirect bilirubin (I-Bil) and direct bilirubin (D-Bil) were performed. The levels of sidt $2^{-/}$mouse serum AST, ALT, T-CHOL, TG, LDL-C, T-Bil, I-Bil and D-Bil were significantly higher than those of sidt $2^{+/+}$mice (Fig. 2). However, the serum HDL-C in the sidt $2^{-/}$mouse group was significantly lower compared with the sidt $2^{+/+}$control group (Fig. 2E). Serum TG, T-CHOL, HDL-C and LDL-C levels reflect the status of lipid metabolism in the body. Compared with sidt $2^{+/+}$mice, the serum TG, T-CHOL and HDL-C levels were increased in the sidt $2^{-/}$mice, whereas LDL-C was decreased, thus indicating lipid metabolic disorder. The serum T-Bil, D-Bil, I-Bil, AST and ALT levels were higher in the $\operatorname{sidt} 2^{-/-}$mice, and were indicators of hepatic cell function. By measuring the levels of these serum components in the mice, it was demonstrated that the sidt $2^{-/-}$mice had abnormal liver functions.

Morphological changes of the liver in sidt $2^{-/}$mice. The colors of sidt $2^{+/+}$mouse livers were pink, whereas in sidt $2^{-1-}$ mice the livers were more yellow and appeared fatty. Sidt $2^{+/+}$ mouse livers appeared uniformly soft, but $\operatorname{sidt}^{2 /-}$ mouse livers were not. The envelopes were tight and smooth, and the edges of the liver appeared dull (Fig. 3A and B). There was no marked difference in liver volume of the sidt $2^{-/}$mice compared with the sidt $2^{+/+}$mice. The morphologies of sidt $2^{+/+}$ and sidt $2^{-/-}$mice liver frozen sections stained with $\mathrm{H} \& \mathrm{E}$ and Oil Red $\mathrm{O}$ were observed via optical microscopy. sidt $2^{+/+}$liver cells were polygonal in shape, nuclei were large and round, and were located in the middle of the cell, and the cytoplasm was eosinophilic, with basophilic briquettes distributed in the cytoplasm. The sidt $2^{-/}$mouse liver samples exhibited large fatty drops in the cytoplasm of the hepatocytes, abutting the nucleus and the borders of the cytoplasm towards the cell membrane. Liver cell swelling and cytoplasmic loss was also observed. The cytoplasm appeared transparent and blebs were noted. Occasionally, the cell volume appeared smaller and dehydrated, with strong eosinophilic deep red staining around necrotic bodies known as Mallory bodies (Fig. 3C and D). The morphology of livers in the sidt $2^{+/+}$mice were also observed via optical microscopy and Oil Red $\mathrm{O}$ staining, and no lipid droplet deposition was observed. However in the sidt $2^{-/-}$mice, many large lipid droplets were observed (Fig. 3E and F). TEM observations indicated liver steatosis (Fig. 3G), as revealed by membrane lipid droplets in the cell liver cytoplasm, and some apoptotic body formation (Fig. 3H).

Mitochondrial damage and LMP-related indices in sidt $2^{-/-}$mice. Mitochondria are enclosed by two membranes; a smooth outer membrane and an inner membrane that is folded into an array of contiguous layers, which are known as cristae. Sidt $2^{-/-}$mouse liver samples were observed with TEM and demonstrated to have mitochondrial edema, eventually destroying the mitochondrial integrity (Fig. 4A and B). The $\mathrm{Fe}^{2+}$ levels in 

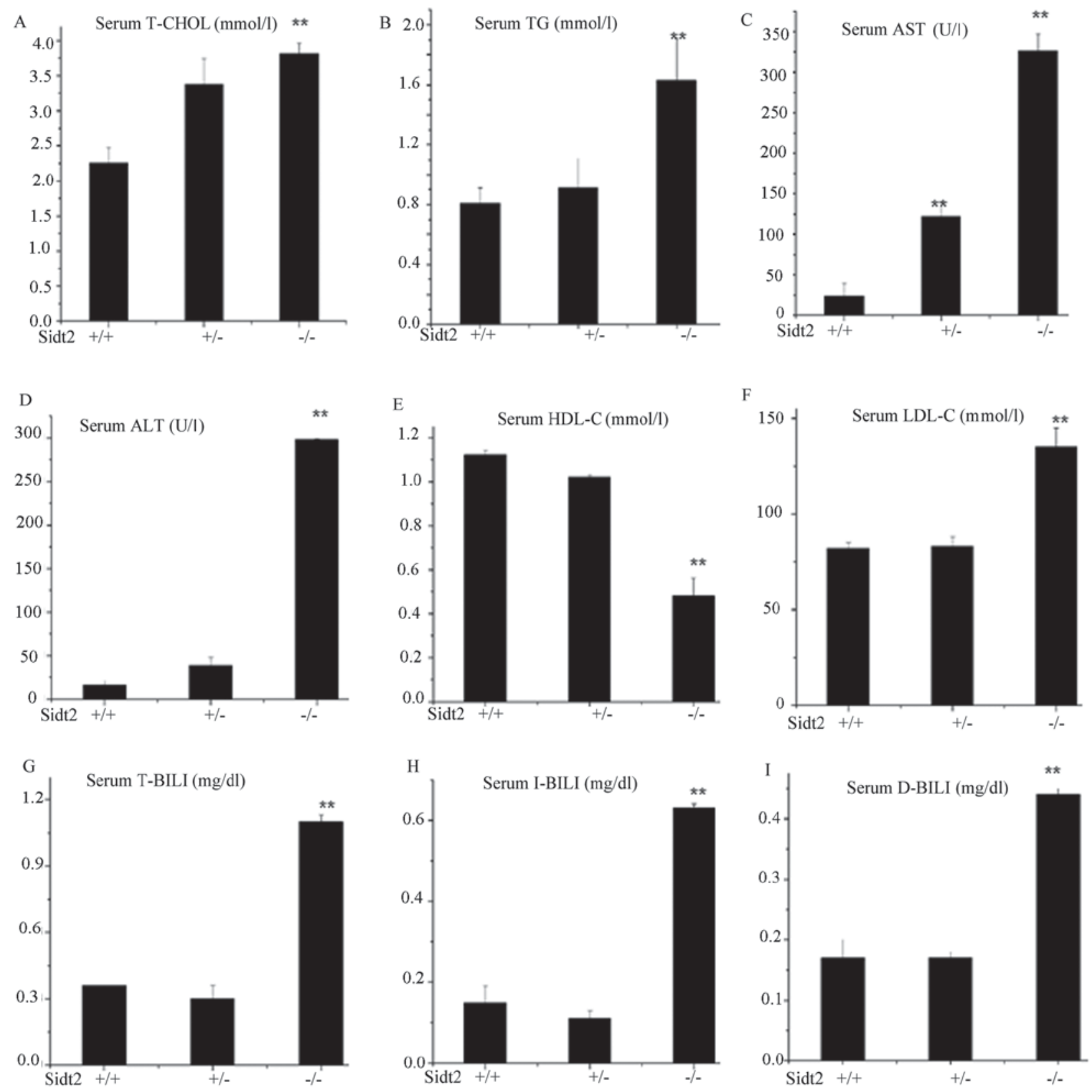

Figure 2. Changes of serum biochemical parameters in sidt2 ${ }^{-/}$mice. (A) T-CHOL, (B) TG, (C) AST, (D) ALT, (E) HDL-C, (F) LDL-C, (G) T-BIL, (H) I-BIL and (I) D-BIL concentrations were analyzed by enzymatic methods. Data are expressed as the mean \pm standard error of the mean $(n=8)$. ${ }^{* *} \mathrm{P}<0.01 \mathrm{vs}$. sidt2 ${ }^{+/+}$. Sidt2, SID1 transmembrane family member 2; T-CHOL, total cholesterol; TG, total triglycerides; AST, aspartate transaminase; ALT, alanine transaminase; HDL-C, high density lipoprotein cholesterol; LDL-C, low density lipoprotein cholesterol; T-BIL, total bilirubin; I-BIL, indirect bilirubin; D-BIL, direct bilirubin.

the sidt $2^{-/-}$mouse livers were increased and the $\mathrm{Fe}^{3+}$ levels were decreased when compared with the sidt $2^{+/+}$mouse livers (Fig. 4C). However, the total Fe levels were not significantly different in the two groups. Hydrogen peroxide $\left(\mathrm{H}_{2} \mathrm{O}_{2}\right)$ and NO typically originate from the mitochondria. Because of this mitochondrial damage, $\mathrm{H}_{2} \mathrm{O}_{2}$ and $\mathrm{NO}$ levels were detected in liver tissue homogenates, and observed that they increased significantly compared with the levels in sidt $2^{+/+}$mice (Fig. 4D).

\section{Discussion}

In the present study, the changes of serum basal levels of T-CHOL, TG, LDL-C and HDL-C were investigated in 6-month-old male sidt $2^{-/-}$mice maintained on a normal diet. It was demonstrated that sidt $2^{-/-}$serum T-CHOL, TG and LDL-C levels were increased significantly compared with sidt $2^{+/+}$mice, but serum HDL-C was decreased. This was demonstrated as a spontaneous disorder of lipid metabolism. However, in sidt $^{-/-}$mice, serum AST, ALT, T-Bil, D-Bil and I-Bil increased compared with those of sidt $2^{+/+}$mice, suggesting that the sidt $2^{-/-}$mice not only had a disorder of lipid metabolism, but that liver function was also impaired.

Light microscopy of sidt $2^{-/-}$mouse liver sections observed following $H \& E$ staining demonstrated that numerous lipid droplets accumulated in liver cells. The liver cells were round and swollen and Mallory bodies, a sign of liver cell necrosis, 

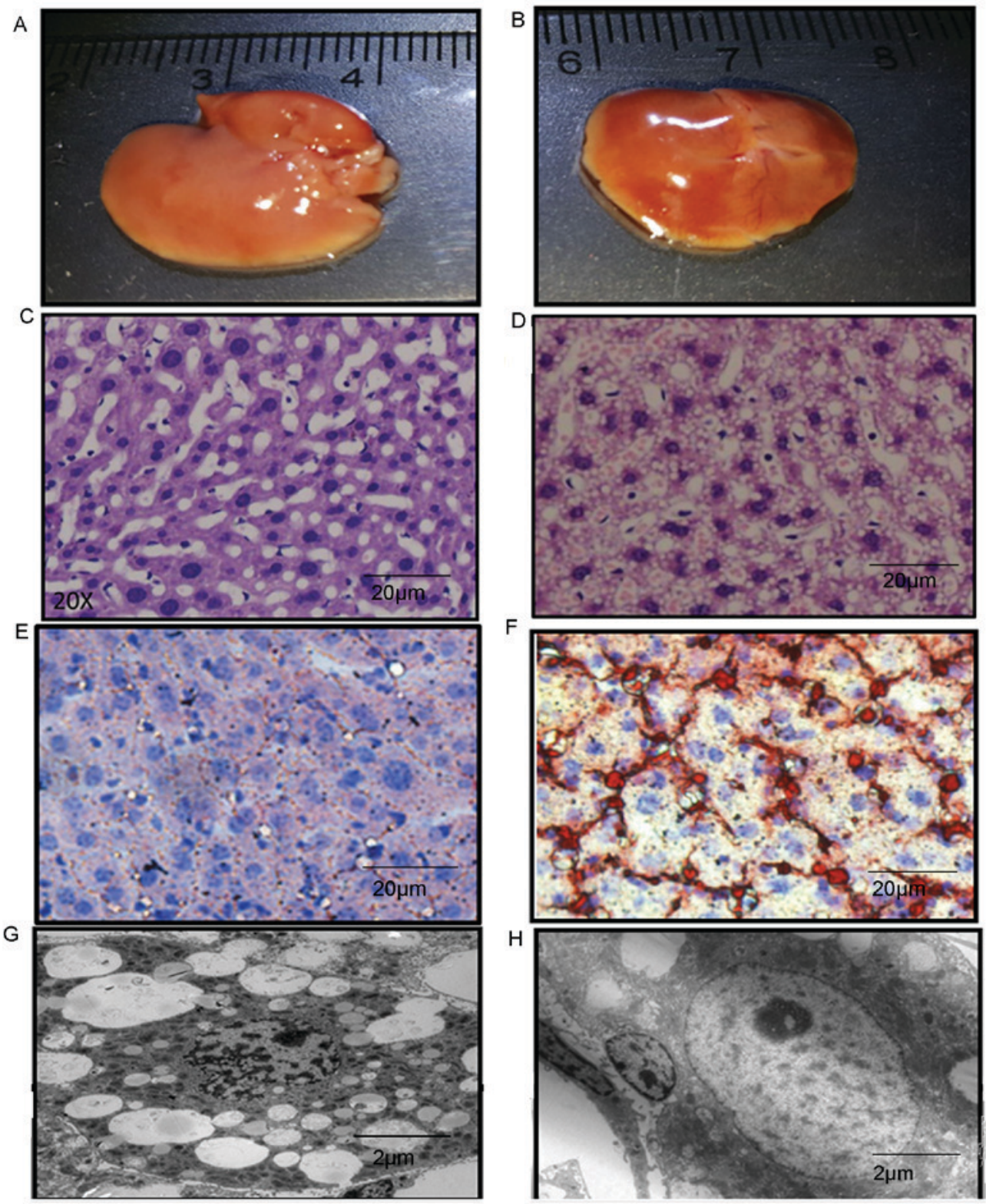

Figure 3. Morphological changes of the liver in sidt $2^{+/+}$and sidt $2^{-/}$mice. General morphology of (A) sidt $2^{+/+}$and (B) sidt $2^{-/}$mice liver samples. Hematoxylin and eosin staining of (C) sidt2 $2^{+/+}$and (D) sidt $2^{-/}$mice liver samples. Oil Red O staining of (E) sidt $2^{+/+}$and (F) sidt $2^{-/}$mice liver samples. Ultrastructure of $(\mathrm{G})$ sidt $2^{+/+}$ and $(\mathrm{H})$ sidt 2 - $^{--}$mice liver samples by transmission electron microscopy. Sidt2, SID1 transmembrane family member 2.

were observed. Oil Red O staining and light microscopy revealed numerous large lipid droplets, suggesting that pathological changes had occurred in the livers of the sidt $2^{-/}$mice, and that liver function was impaired and was accompanied by necrosis. Using TEM of sidt $2^{--}$liver sections, mitochondria edema was observed, and mitochondrial cristae were separated from the mitochondrial matrix and exhibited vacuole-like changes.

Mitochondrial cristae act as folding units to create the mitochondrial matrix, lying inside of the inner membrane, and an outer compartment known as the intermembrane space, which lies between the mitochondrial membranes. Mitochondria are important subcellular organelles involved in lipid metabolism (9). The free fatty acids for $\beta$-oxidation that occur in the mitochondria of liver cells may be decreased from swelling or vacuole-like changes to the liver cell mitochondria of sidt $2^{-/}$mice. Free fatty acids will then accumulate to form lipid droplets, eventually causing apoptosis, fatty liver disease, and permanent damage to the liver (10).

Under normal physiological conditions, the lysosome uses many proteins for endocytosis (11) and autophagy (12). These proteins bind to redox-reactive iron $\left(\mathrm{Fe}^{2+}\right)$ leading to a concentration decrease of $\mathrm{Fe}^{2+}$ in the lysosome, thereby stabilizing the lysosomal membrane (13). Normally, the lysosome is not sensitive to oxidative stress. However, in the present study, it was demonstrated that in sidt $2^{--}$mouse liver tissues and in liver cell lysosomes the redox-reactive iron $\left(\mathrm{Fe}^{2+}\right)$ increased. Increased $\mathrm{Fe}^{2+}$ can change $\mathrm{H}_{2} \mathrm{O}_{2}$ to hydroxyl radicals via the Fenton reaction (14). Hydroxyl radicals attack the lysosomal membrane, making it more sensitive to oxidative stress (15). If oxidative stress occurs in the cell, the resulting lysosomal membrane instability may lead to lysosomal membrane 
A a

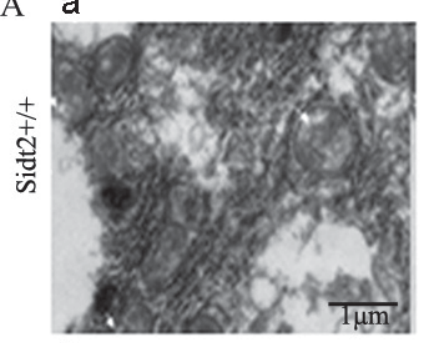

B a

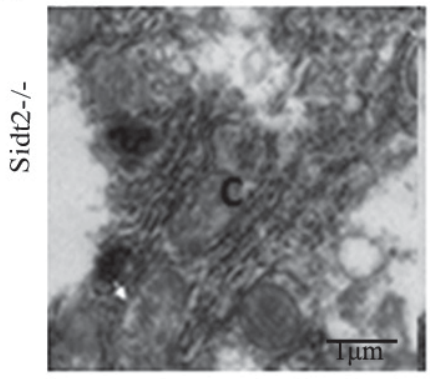

$\mathrm{C}$

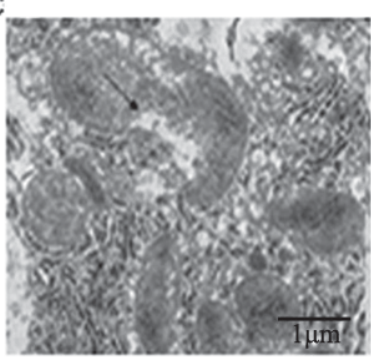

b

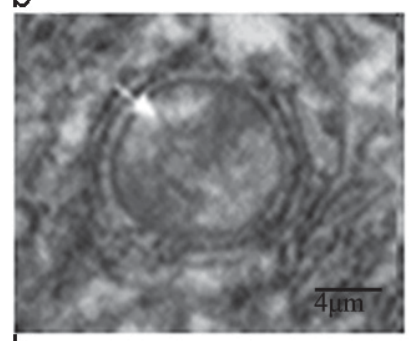

b

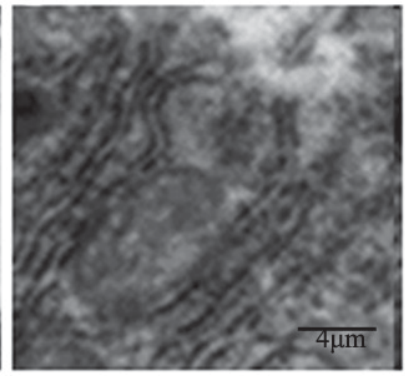

d

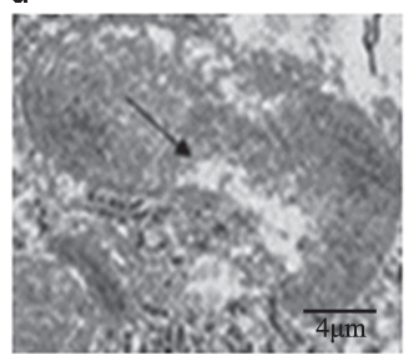

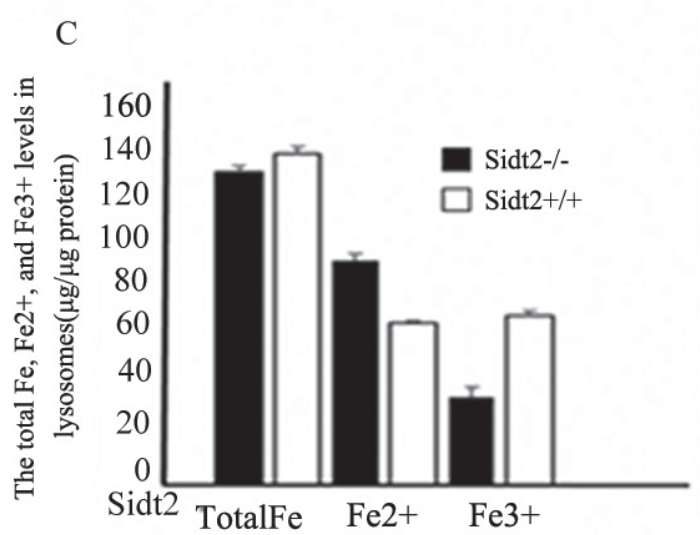

D
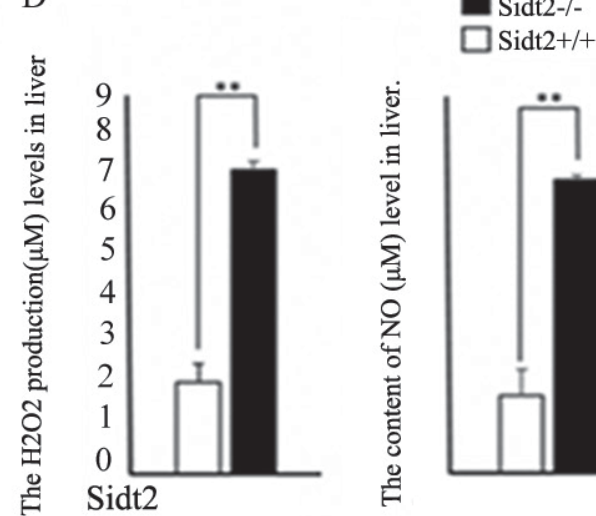

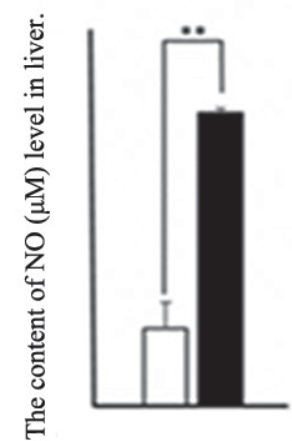

Figure 4. Mitochondrial damage and lysosomal membrane permeabilization-related indices in sidt $2^{-/-}$mice. The black arrows indicate where mitochondrial edema and destruction occurred. (A) Sidt $2^{+/+}$mouse liver samples observed via TEM indicating the mitochondrial integrity. Ab is a magnification of Aa. (B) The sidt $2^{-/}$mouse liver samples observed via TEM. (Ba) Edema. (Bb) Disrupted mitochondria. Bb and Bd are amplifications of Ba and Bc. Magnification, x12,000. (C) The total Fe, $\mathrm{Fe}^{2+}$, and $\mathrm{Fe}^{3+}$ levels of the sidt $2^{+/+}$and sidt $2^{-/-}$mouse lysosome samples. (D) $\mathrm{H}_{2} \mathrm{O}_{2}$ and $\mathrm{NO}_{\text {levels }}$ in sidt2 $2^{+/+}$and sidt $2^{-/-}$mouse liver tissue homogenates. Concentrations were analyzed via enzymatic methods. Data are expressed as the mean \pm standard error of the mean $(n=8)$. ${ }^{* *}<<0.01$. Sidt 2 , SID1 transmembrane family member 2; TEM, transmission electron microscopy.

peroxidation (16). Due to the damaged mitochondria in sidt $2^{-/-}$mice liver cells, the resulting abnormal release of $\mathrm{H}_{2} \mathrm{O}_{2}$ and NO even at low concentrations would induce LMP (17) once they diffused into the cytoplasm and directly damaged the lysosome membranes. Hydroxyl radicals attack the lysosomal membrane, destroy its integrity, and lead to lysosomal membrane disintegration through LMP (18). The lysosome contains $>50$ soluble acid hydrolases, and when its membrane collapses the lysosomal contents leak. The leakage of lysosomal constituents is suggested to be sufficient to trigger other organelle damage, particularly the mitochondria (19). Mitochondrial damage may also cause the release of $\mathrm{H}_{2} \mathrm{O}_{2}(18)$, which, in turn, destroys the lysosome membrane (10), and leads to cell death in a caspase-dependent or independent manner. These changes lead to liver cell apoptosis and functional liver disorders.

It has previously been demonstrated that sidt 2 is a novel lysosomal membrane protein (3). It was demonstrated in the present study that when this protein is deleted LMP occurs, thus confirming that sidt 2 is a key protein in the LMP response. However, the specific mechanism whereby sidt 2 causes LMP is unclear, and requires further study. The changes of liver function and lipid metabolism can be observed under a normal diet. To better understand the role of sidt2, sidt 2 deficiency mice can be challenged by HFD, or MCD. The use of a normal diet is a limitation of the present study, and future studies should make use of a high-fat diet to observe changes in liver function. The results of the present study revealed that sidt 2 knockout mice exhibit pathological and metabolic changes, which provides an important theoretical basis for further study and a basis for the understanding of lysosomes and disease.

\section{Acknowledgements}

The authors would like to thank Dr Jialin Gao (Department of Endocrinology and Genetic Metabolism, Yijishan Hospital of Wannan Medical College, Wuhu, China) for their technical assistance.

\section{Funding}

The present study was supported by grants from the National Natural Science Foundation of China (grant nos. 81200632 and 81471002), the Natural Science Foundation of Anhui, China (grant no. 1308085QH134), and the Introduction of Talents Foundation of Yijishan Hospital (grant no. YR201104). 


\section{Availability of data and materials}

The datasets used and/or analyzed during the current study are available from the corresponding author on reasonable request.

\section{Authors' contributions}

LW conceived and designed the experiments and provided relevant materials and analytical tools. YM performed the experiments. LL analyzed the data.

\section{Ethics approval and consent to participate}

Animal experiments were reviewed and approved by the Animal Ethics Committee of Wannan Medical College.

\section{Consent for publication}

Not applicable.

\section{Competing interests}

The authors declare that they have no competing interests.

\section{References}

1. Yu F, Chen Z, Wang B, Jin Z, Hou Y, Ma S and Liu X: The role of lysosome in cell death regulation. Tumour Biol 37: 1427-1436, 2016.

2. Appelqvist H, Waster P, Kagedal K and Ollinger K: The lysosome: From waste bag to potential therapeutic target. J Mol Cell Biol 5: 214-226, 2013.

3. Gao J, Yu C, Xiong Q, Zhang Y and Wang L: Lysosomal integral membrane protein Sidt 2 plays a vital role in insulin secretion. Int J Clin Exp Pathol 8: 15622-15631, 2015.

4. Pryor PR and Luzio JP: Delivery of endocytosed membrane proteins to the lysosome. Biochim Biophys Acta 1793: 615-624, 2009.

5. Oberle C, Huai J, Reinheckel T, Tacke M, Rassner M, Ekert PG, Buellesbach J and Borner C: Lysosomal membrane permeabilization and cathepsin release is a Bax/Bak-dependent, amplifying event of apoptosis in fibroblasts and monocytes. Cell Death Differ 17: 1167-1178, 2010.
6. Gao J, Gu X, Mahuran DJ, Wang Z and Zhang H. Impaired glucose tolerance in a mouse model of sidt 2 deficiency. PloS One 8: e66139, 2013.

7. Jialin G, Xuefan G and Huiwen Z: SID1 transmembrane family, member 2 (Sidt2): A novel lysosomal membrane protein. Biochem Biophys Res Commun 402: 588-594, 2010.

8. Thomas DM, Ferguson GD, Herschman HR and Elferink LA: Functional and biochemical analysis of the $\mathrm{C} 2$ domains of synaptotagmin IV. Mol Biol Cell 10: 2285-2295, 1999.

9. Fulda S, Galluzzi L and Kroemer G: Targeting mitochondria for cancer therapy. Nat Rev Drug Discov 9: 447-464, 2010.

10. Li Z, Berk M, McIntyre TM, Gores GJ and Feldstein AE: The lysosomal-mitochondrial axis in free fatty acid-induced hepatic lipotoxicity. Hepatology 47: 1495-1503, 2008.

11. Antunes F, Cadenas E and Brunk UT: Apoptosis induced by exposure to a low steady-state concentration of $\mathrm{H} 2 \mathrm{O} 2$ is a consequence of lysosomal rupture. Biochem J 356: 549-555, 2001.

12. Kurz T, Terman A and Brunk UT: Autophagy, ageing and apoptosis: The role of oxidative stress and lysosomal iron. Arch Biochem Biophys 462: 220-230, 2007.

13. Terman A and Kurz T: Lysosomal iron, iron chelation, and cell death. Antioxid Redox Signal 18: 888-898, 2013.

14. Schubert D and Chevion M: The role of iron in beta amyloid toxicity. Biochem Biophys Res Commun 216: 702-707, 1995.

15. Risin SA and Penkratova NN: Effect of unfractionated histones on isolated mouse liver lysosomes. Vopr Med Khim 26: 752-755, 1980 (In Russian).

16. Boya P and Kroemer G: Lysosomal membrane permeabilization in cell death. Oncogene 27: 6434-6451, 2008.

17. Yin L, Stearns R and Gonzalez-Flecha B: Lysosomal and mitochondrial pathways in $\mathrm{H} 2 \mathrm{O} 2$-induced apoptosis of alveolar type II cells. J Cell Biochem 94: 433-445, 2005.

18. Mak IT, Misra HP and Weglicki WB: Temporal relationship of free radical-induced lipid peroxidation and loss of latent enzyme activity in highly enriched hepatic lysosomes. J Biol Chem 258: 13733-13737, 1983.

19. Groth-Pedersen L and Jäättelä M: Combating apoptosis and multidrug resistant cancers by targeting lysosomes. Cancer Lett 332: 265-274, 2013.

c) (7) $\odot$ This work is licensed under a Creative Commons

(c) At NG ND Atribution-NonCommercial-NoDerivatives 4.0 International (CC BY-NC-ND 4.0) License. 